\title{
Is Dose Adjustment Based on Several Factors of Body Size Descriptors Effective for Prevention of Thrombocytopenia by Linezolid Therapy in Hemodialysis Patients?
}

\author{
Hideo Kato1,2, Mao Hagihara1,2, Yuka Yamagishi', Yukihiro Hamada1,2, Jun Hirai1, Naoya Nishiyama1, \\ Yusuke Koizumi', Katsuhiko Matsuura ${ }^{2}$, Hiroshige Mikamo ${ }^{{ }^{*}}$
}

${ }^{1}$ Department of Infection Control and Prevention, Aichi Medical University School of Medicine, Nagakute, Japan

${ }^{2}$ Department of Pharmacy, Aichi Medical University School of Medicine, Nagakute, Japan

Email:^mikamo@aichi-med-u.ac.jp, *mikamo@muc.biglobe.ne.jp

How to cite this paper: Kato, H., Hagihara, M., Yamagishi, Y., Hamada, Y., Hirai, J., Nishiyama, N., Koizumi, Y., Matsuura, K. and Mikamo, H. (2016) Is Dose Adjustment Based on Several Factors of Body Size Descriptors Effective for Prevention of Thrombocytopenia by Linezolid Therapy in Hemodialysis Patients? Pharmacology \& Pharmacy, 7, 417-423.

http://dx.doi.org/10.4236/pp.2016.710049

Received: September 15, 2016

Accepted: October 24, 2016

Published: October 27, 2016

Copyright $\odot 2016$ by authors and Scientific Research Publishing Inc. This work is licensed under the Creative Commons Attribution International License (CC BY 4.0).

http://creativecommons.org/licenses/by/4.0/ (c) (†) Open Access

\begin{abstract}
Previous study suggested that low body weight was one of the risk factors of thrombocytopenia induced by linezolid in non-hemodialysis patients. However, there have been little investigations for the linezolid-induced thrombocytopenia in hemodialysis patients. This study was to evaluate the association between several factors of body size descriptors and thrombocytopenia in hemodialysis-patients. No factor of body size descriptors showed significant correlation with linezolid-induced thrombocytopenia (patients with thrombocytopenia vs patients without thrombocytopenia: body weight; $60.0 \mathrm{~kg}$ vs $55.3 \mathrm{~kg}, p=0.82$ : body mass indices; $21.1 \mathrm{~kg} / \mathrm{m}^{2}$ vs $21.2 \mathrm{mg} / \mathrm{m}^{2}, p=$ 0.44 : ideal body weight; $61.2 \mathrm{~kg}$ vs $59.5 \mathrm{~kg}, p=0.21$ : lean body weight; $50.1 \mathrm{~kg}$ vs 45.7 $\mathrm{kg}, p=0.64$ : dosage amount; $20.0 \mathrm{mg} / \mathrm{kg}$ vs $21.7 \mathrm{mg} / \mathrm{kg}, p=0.74$ : body surface area; $1.65 \mathrm{~m}^{2}$ vs $1.54 \mathrm{~m}^{2}, p=0.43$ ). There were not significant differences in the body size descriptors between linezolid therapy for more than 14 days and for less than 13 days (more than 14 days vs less than 13 days: body weight; $53.5 \mathrm{~kg}$ vs $56.8 \mathrm{~kg}, p=0.75$ : body mass indices; $20.9 \mathrm{~kg} / \mathrm{m}^{2}$ vs $21.1 \mathrm{mg} / \mathrm{m}^{2}, p=0.47$ : ideal body weight; $60.3 \mathrm{~kg}$ vs $59.9 \mathrm{~kg}, p=0.17$ : lean body weight; $44.3 \mathrm{~kg}$ vs $47.7 \mathrm{~kg}, p=0.56$ : dosage amount; 22.4 $\mathrm{mg} / \mathrm{kg}$ vs $21.1 \mathrm{mg} / \mathrm{kg}, p=0.67$ : body surface area; $1.51 \mathrm{~m}^{2}$ vs $1.59 \mathrm{~m}^{2}, p=0.37$ ). Our data suggested that dosage adjustment of linezolid based on body weight was not recommended in hemodialysis-patients.
\end{abstract}

\section{Keywords}

Linezolid, Thrombocytopenia, Body Weight 


\section{Introduction}

Linezolid has a broad spectrum of antimicrobial activity against Gram-positive bacteria, including methicillin-resistant Staphylococcus aureus (MRSA) and vancomycin-resistant enterococci (VRE) [1]. One of the major side effects of linezolid is myelosuppression, especially for thrombocytopenia. Takahashi et al. showed low body weight was one of the risk factors of thrombocytopenia induced by linezolid in non-hemodialysis patients [2]. In previous our study, hemodialysis patients exhibited significant higher reduction rates of platelet (PLT) count, compared with non-hemodialysis patients, although the incidence of linezolid-induced thrombocytopenia was equal between hemodialysis patients and non-hemodialysis patients [3]. However, there have been little investigations for the linezolid-induced thrombocytopenia in hemodialysis patients. Therefore, we researched the association between body size descriptors and linezolidinduced thrombocytopenia in Japanese hemodialysis patients to see if adjusted dosage amount with body size descriptors prevents linezolid-induced thrombocytopenia.

\section{Patients and Methods}

\subsection{Patients}

A retrospective study was conducted among hemodialysis patients treated with linezolid therapy (600 mg q $12 \mathrm{~h}$ ) by the oral or parenteral route between January 2010 and July 2012 at Aichi Medical University Hospital (995 beds). All subjects were dialyzed with an APS-SA dialyzer (polysulfone; surface area, $1.5 \mathrm{~m}^{2}$ ) or a FDX-GW (polyester polymer alloy; surface area, $1.5 \mathrm{~m}^{2}$ ) for 3 or 4 hours and the flow rate of dialyzer was 150 - $250 \mathrm{~mL} / \mathrm{min}$. Inclusion criteria were as follows: age of $>18$ years; adequate samples of blood or wound, urine specimens for microbiological culture, as indicated by clinical signs. Patients were excluded from the study if a period of linezolid therapy was less than $48 \mathrm{~h}$. The study was reviewed and approved by the ethics committee of Aichi Medical University Hospital.

\subsection{Data Collection}

The blood sampling was performed at appropriate times from the start of linezolid therapy to 1 month after administration of linezolid. Nine variables: sex, age, body weight, duration of linezolid therapy, serum creatinine, estimated glomerular filtration rate (eGFR), platelet (PLT), albumin (Alb) and blood urea nitrogen (BUN) were analyzed as baseline before linezolid initiation. Thrombocytopenia was defined as $>50 \%$ platelet count decrease from baseline. Body size descriptors (body weight, body mass index (BMI), ideal body weight (IBW), lean body weight (LBW), dosage amount and body surface area) were analyzed. BMI was calculated by dividing the patient's body weight in kilograms by the square of their height in meters [4]. IBW was calculated as followed; IBW $=22 \times(\text { height in } \mathrm{m})^{2}(\mathrm{~kg})$ [4]. LBW, in kilograms, was calculated by the method of Janmahasatian and colleagues: LBW (males $)=(9270 \times$ body weight $) /[6680+$ $(216 \times \mathrm{BMI})]$; LBW $($ females $)=(9270 \times$ body weight $) /[8780+(244 \times \mathrm{BMI})](\mathrm{kg})[5]$. Body surface area was calculated by the method of Fujimoto: body surface area $=$ 
$0.008883 \times(\text { height in } \mathrm{cm})^{0.663} \times(\text { body weight })^{0.444}\left(\mathrm{~m}^{2}\right)[6]$.

\subsection{Statistical Analysis}

Parametric variables were analyzed using unpaired $t$-test, while nonparametric variables were analyzed using chi-square test. A $p$ value of $<0.05$ was considered as significant difference. Statistical analysis was performed with JMP, version 10.0 (SAS, Tokyo, Japan).

\section{Results}

A total of 68 patients were included in this analysis. The median age was 69 years. Median body weight was $56.4 \mathrm{~kg}$. Median dosage amount [range] of linezolid was 21.3 $\mathrm{mg} / \mathrm{kg} /$ day [15.0 - $32.5 \mathrm{mg} / \mathrm{kg} /$ day]. Median duration of linezolid therapy was 9 days [3 - 34 days]. Linezolid-induced thrombocytopenia was found in 30 of 68 patients (44\%). And linezolid-induced thrombocytopenia was found in 40 of 113 non-hemodialysis patients $(35 \%)$ in a period similar to this study (data not shown). There were not significant differences in the body size descriptors between patients with and without thrombocytopenia (Table 1). Moreover, there were not significant differences in duration of linezolid therapy between hemodialysis and non-hemodialysis (Table 1, Figure 1). When patients were categorized into 3 groups using 2 cut-off values $(17,22 \mathrm{~kg} / \mathrm{mg} / \mathrm{day})$ of dosage amount, the prevalence of thrombocytopenia in each groups was not significantly different (Reduction rate of $>25 \%$; $<17 \mathrm{mg} / \mathrm{kg} /$ day $(69.2 \%), 17-22 \mathrm{mg} / \mathrm{kg} / \mathrm{day}$ (69.2\%), $>22 \mathrm{mg} / \mathrm{kg} /$ day (75.9\%), $p=0.90$ : Reduction rate of $>50 \%$; $<17 \mathrm{mg} / \mathrm{kg} / \mathrm{day}$ (38.5\%), 17 - $22 \mathrm{mg} / \mathrm{kg} /$ day (50.0\%), $>22 \mathrm{mg} / \mathrm{kg} /$ day $(44.8 \%), p=0.84)$.

Table 1. Linezolid associated thrombocytopenia ( $>50 \%)$ in hemodialysis patients.

\begin{tabular}{cccc}
\hline \multicolumn{2}{c}{ Patients with thrombocytopenia } & Patients without thrombocytopenia & $p$ value \\
\hline Patients number (male/female) & $30(25 / 5)$ & $38(33 / 5)$ & 0.69 \\
Age (year) & $68[22-92]$ & $69[34-87]$ & 0.72 \\
Dosage amount $(\mathrm{mg} / \mathrm{kg})$ & $20.0[15.3-30.9]$ & $21.7[15.0-32.5]$ & 0.74 \\
Duration of linezolid therapy (day) & $9[4-34]$ & $8[3-21]$ & 0.08 \\
Platelet $\left(\times 10^{3} \mu \mathrm{L}\right)$ & $161[14-572]$ & $202[36-779]$ & 0.30 \\
Albumin $(\mathrm{g} / \mathrm{dL})$ & $2.5[1.7-3.4]$ & $2.7[1.6-3.7]$ & 0.16 \\
Serum creatinine $(\mathrm{mg} / \mathrm{dL})$ & $3.42[1.25-8.28]$ & $1.61[1.18-16.95]$ & 0.80 \\
eGFR (mL/min/1.73 m²) & $15.5[5-51]$ & $15[3-59]$ & 0.53 \\
Blood urea count $(\mathrm{mg} / \mathrm{dL})$ & $39.7[8.8-87]$ & $30.2[0.45-102.8]$ & 0.30 \\
Body weight $(\mathrm{kg})$ & $60.0[38.8-78.6]$ & $55.3[36.9-80]$ & 0.82 \\
Body mass indices $\left(\mathrm{kg} / \mathrm{m}^{2}\right)$ & $21.1[14.8-29.2]$ & $21.2[15.8-28.2]$ & 0.44 \\
Ideal body weight $(\mathrm{kg})$ & $61.2[46.9-66.6]$ & $59.5[44.4-67.4]$ & 0.21 \\
Lean body weight $(\mathrm{kg})$ & $50.1[29.0-58.8]$ & $45.7[26.6-58.6]$ & 0.64 \\
Body surface area $\left(\mathrm{m}^{2}\right)$ & $1.65[1.28-1.88]$ & $1.54[1.12-1.87]$ & 0.43 \\
\hline
\end{tabular}

Chi-squared test for categorical data and unpaired $t$-test for continuous data. All data, except gender, are shown as the median [min-max]. eGFR; estimated glomerular filtration rate. 

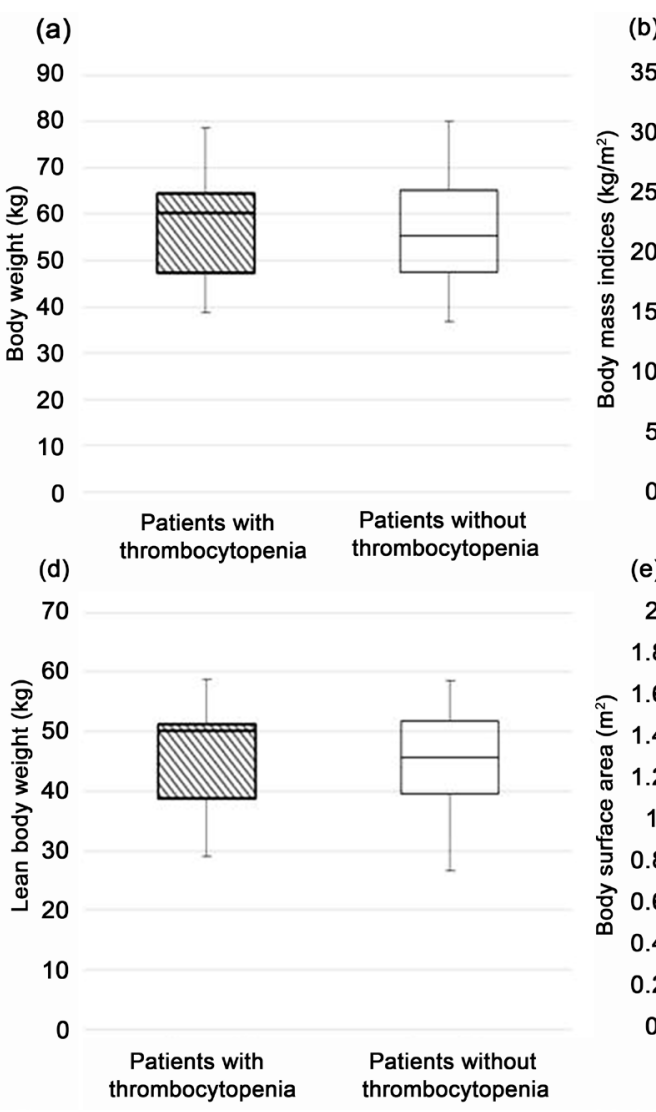

(b)

35

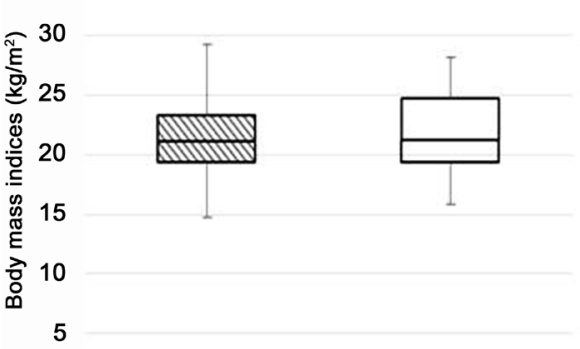

0

(e)

Patients with thrombocytopenia

Patients without thrombocytopenia

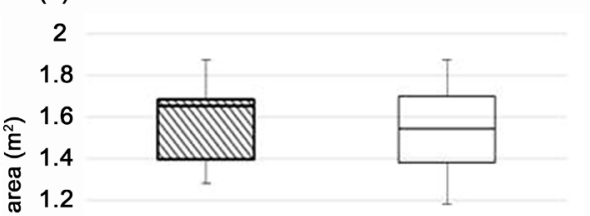

.

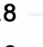
0.6 0.2

0

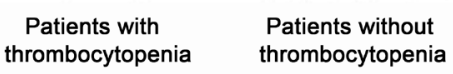

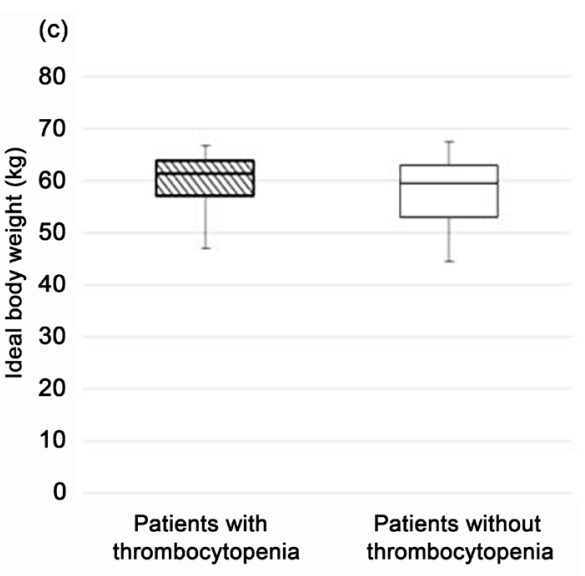

Figure 1. Body size descriptors body weight (a), body mass index (b), ideal body weight (c), lean body weight (d) and body surface area (e) patients with thrombocytopenia, $\mathrm{n}=30$; patients without thrombocytopenia, $\mathrm{n}=38$.

While prolonged treatment duration for more than 14 days has been reported as risk factors for linezolid-induced thrombocytopenia [7], the proportion of patients with thrombocytopenia did not show significant difference between patients with linezolid therapy for more than 14 days and patients with linezolid therapy for less than 13 days in our study $(40.0 \%$ vs $45.3 \%, p=0.87$, Table 2$)$. There were not significant differences in the body size descriptors between linezolid therapy for more than 14 days and for less than 13 days (Table 2).

\section{Discussion}

Hemodialysis patients exhibited a significant higher reduction rate of PLT count, compared with non-hemodialysis patients [3]. Prolonged treatment duration [7], renal insufficiencies [8], chronic liver disease [8] and lower body weight [2] have been reported as possible risk factors for linezolid-induced thrombocytopenia. Additionally, Natsumoto et al. showed that both higher daily dose (mg/kg/day) (prevalence of thrombocytopenia; <17 mg/kg/day (17\%), 17 - $22 \mathrm{mg} / \mathrm{kg} /$ day (34\%), 22 - $27 \mathrm{mg} / \mathrm{kg} /$ day (48\%), >27 $\mathrm{mg} / \mathrm{kg} /$ day $(72 \%))$ and elevated serum creatinine were significant risk factors for linezolid-induced thrombocytopenia in non-hemodialysis patients [9]. However, we usually administer linezolid with usual dosage $(600 \mathrm{mg} \mathrm{q} 12 \mathrm{~h})$ to hemodialysis patients. 
Table 2. Duration linezolid therapy in hemodialysis patients.

\begin{tabular}{cccc}
\hline & More than 14 days & Less than 13 days & $p$ value \\
\hline Patient number (male/female) & $15(12 / 3)$ & $53(46 / 7)$ & 0.64 \\
Patients with thrombocytopenia (\%) & 40.0 & 45.3 & 0.87 \\
Dosage amount $(\mathrm{mg} / \mathrm{kg})$ & $22.4[16.0-32.5]$ & $21.1[15.0-32.4]$ & 0.67 \\
Duration of linezolid therapy (day) & $16[14-34]$ & $8[3-13]$ & 0.08 \\
Body weight $(\mathrm{kg})$ & $53.5[36.9-75.0]$ & $56.8[37-80]$ & 0.75 \\
Body mass indices $\left(\mathrm{kg} / \mathrm{m}^{2}\right)$ & $20.9[15.9-25.4]$ & $21.1[14.8-29.2]$ & 0.47 \\
Ideal body weight $(\mathrm{kg})$ & $60.3[44.4-66.6]$ & $59.9[46.3-67.4]$ & 0.17 \\
Lean body weight $(\mathrm{kg})$ & $44.3[26.6-57.2]$ & $47.7[29.0-58.8]$ & 0.56 \\
Body surface area $\left(\mathrm{m}^{2}\right)$ & $1.51[1.12-1.83]$ & $1.59[1.24-1.88]$ & 0.37 \\
\hline
\end{tabular}

Chi-squared test for categorical data and unpaired $t$-test for continuous data. All data, except gender, are shown as the median [min-max]. eGFR; estimated glomerular filtration rate.

Therefore, we investigated the association between several body size descriptors and linezolid-induced thrombocytopenia in hemodialysis patients. As a consequence, no factors of body size descriptors were the risk factor for linezolid-induced thrombocytopenia (Table 1, Figure 1). Prolonged treatment duration was not the risk factor for linezolid-induced thrombocytopenia in hemodialysis patients, similar with the patients without thrombocytopenia. And the duration of linezolid therapy in the patients with thrombocytopenia was more dispersed compared with the patients without thrombocytopenia. However, When patients were categorized into 2 groups using 1 cut-off values (14 days) of duration of linezolid therapy, the prevalence in each groups was not significantly different $(<14$ days/ $\geq 14$ days: patients with thrombocytopenia; $6 / 24$, patients without thrombocytopenia; 10/28, $p=0.34$ ).

Some previous studies showed that linezolid was removed with hemodialysis. Brier et al. showed approximately $30 \%-50 \%$ of the administered dose of the drug was removed by hemodialysis, but hemodialysis patients had the higher concentration of linezolid than that of non-hemodialysis patients [10]. Despite of the decreasing daily dose of linezolid from 1200 to $600 \mathrm{mg}$ at the start of treatment to prevent thrombocytopenia in a renal dysfunction patient, the concentration of linezolid in the serum was $11.5 \mu \mathrm{g} / \mathrm{mL}$ on 21st day of linezolid therapy, which was sufficient to induce thrombocytopenia [11]. Additionally, they reported that linezolid concentration was similar between the wound exudate and serum [11]. Therefore, we thought that thrombocytopenia in hemodialysis patients was associated with the accumulation of linezolid. In this study, there was not significant difference in LBW between hemodialysis patients with thrombocytopenia and without thrombocytopenia. The association between linezolid concentration in target tissue and serum with thrombocytopenia would require further investigation including measure of linezolid concentration. Additionally, one of the stratagems might be therapeutic drug monitoring (TDM) of linezolid to prevent thrombocytopenia. However, TDM of linezolid in many hospitals including our hospital is not the practical 
way we can conduct due to the cost. Therefore, we should monitor PLT count during the treatment with linezolid, and our data would be useful to decide the linezolid dosage regimen for hemodialysis patients in many practical settings.

However, several considerations should be noted when interpreting our results. The first, this was a retrospective analysis. There were no randomizations among two groups. The second, we did not measure waist, hip and serum triglyceride to reveal the health condition. Therefore, the clinical data in two patients requires further investigation.

\section{Conclusion}

In conclusion, no body size descriptors were involved in the risk factor for linezolidinduced thrombocytopenia in hemodialysis patients. Therefore, our data suggested that the daily dose of linezolid in hemodialysis patients needed not to be adjusted by body size descriptors. It's deemed desirable to administer the usual dose (600 $\mathrm{mg} \mathrm{q} 12 \mathrm{~h}$ ) in hemodialysis patients.

\section{Disclosures}

No conflict of interest is declared.

\section{References}

[1] Stevens, D.L., Herr, D., Lampiris, H., Hunt, J.L., Batts, D.H. and Hafkin, B. (2002) Linezolid versus Vancomycin for the Treatment of Methicillin-Resistant Staphylococcus aureus Infection. Clinical Infectious Diseases, 34, 1481-1490. http://dx.doi.org/10.1086/340353

[2] Takahashi, Y., Takesue, Y., Nakajima, K., Ichiki, K., Tsuchida, T., Tatsumi, S., Ishihara, M., Ikeuchi, H and Uchino, M. (2011) Risk Factors Associated with the Development of Thrombocytopenia in Patients Who Received Linezolid Therapy. Journal of Infection and Chemotherapy, 17, 382-387. http://dx.doi.org/10.1007/s10156-010-0182-1

[3] Kato, H., Hamada, Y., Hagihara, M., Hirai, J., Yamagishi, Y., Matsuura, K. and Mikamo, H. (2015) Bicytopenia, Especially Thrombocytopenia in Hemodialysis and Non-Hemodialysis Patients Treated with Linezolid Therapy. Journal of Infection and Chemotherapy, 21, 707712. http://dx.doi.org/10.1016/j.jiac.2015.06.007

[4] Lemmens, H.J., Brodsky, J.B. and Bernstein, D.P. (2005) Estimating Ideal Body Weight-A New Formula. Obesity Surgery, 15, 1082-1083. http://dx.doi.org/10.1381/0960892054621350

[5] Janmahasatian, S., Duffull, S.B., Ash, S., Ward, L.C., Byrne, N.M. and Green, B. (2005) Quantification of Lean Body Weight. Clinical Pharmacokinetics, 44, 1051-1065. http://dx.doi.org/10.2165/00003088-200544100-00004

[6] Fujimoto, S., Watanabe, T., Sakamoto, A., Yukawa, K. and Morimoto, K. (1968) Studies on the Physical Surface area of Japanese. 18. Calculation Formulae in Three Stages over All Ages. Nippon Eiseigaku Zasshi, 5, 443-450. http://dx.doi.org/10.1265/jih.23.443

[7] Hirano, R., Sakamoto, Y., Tachibana, N. and Ohnishi, M. (2014) Retrospective Analysis of the Risk Factors for Linezolid-Induced Thrombocytopenia in Adult Japanese Patients. International Journal of Clinical Pharmacy, 36, 795-799. http://dx.doi.org/10.1007/s11096-014-9961-6

[8] Sasaki, T., Takane, H., Ogawa, K., Isagawa, S., Hirota, T., Higuchi, S., Horii, T., Otsubo, K. and Ieiri I. (2011) Population Pharmacokinetic and Pharmacodynamics Analysis of Linezolid 
and a Hematologic Side Effect, Thrombocytopenia, in Japanese Patients. Antimicrobial Agents and Chemotherapy, 55, 1867-1873. http://dx.doi.org/10.1128/AAC.01185-10

[9] Natsumoto, B., Yokota, K., Omata, F. and Furukawa, K. (2014) Risk Factors for LinezolidAssociated Thrombocytopenia in Adult Patients. Infection, 42, 1007-1012.

http://dx.doi.org/10.1007/s15010-014-0674-5

[10] Brier, M.E., Stalker, D.J., Aronoff, G.R., Batts, D.H., Ryan, K.K., O’Grady, M., Hopkins, N.K. and Jungbluth, G.L. (2003) Pharmacokinetics of Linezolid in Subjects with Renal Dysfunction. Antimicrobial Agents and Chemotherapy, 47, 2775-2780.

http://dx.doi.org/10.1128/AAC.47.9.2775-2780.2003

[11] Tsuji, Y., Tashiro, M., Ashizawa, N., Ota, Y., Obi, H., Nagura, S., Narukawa, M., Fukahara, K., Yoshimura, N., To, H. and Yamamoto, Y. (2015) Treatment of Mediastinitis Due to Methicillin-Resistant Staphylococcus aureus in a Renal Dysfunction Patient Undergoing Adjustments to the Linezolid Dose. Internal Medicine, 54, 235-239.

http://dx.doi.org/10.2169/internalmedicine.54.2292

\section{Submit or recommend next manuscript to SCIRP and we will provide best service for you:}

Accepting pre-submission inquiries through Email, Facebook, LinkedIn, Twitter, etc. A wide selection of journals (inclusive of 9 subjects, more than 200 journals)

Providing 24-hour high-quality service

User-friendly online submission system

Fair and swift peer-review system

Efficient typesetting and proofreading procedure

Display of the result of downloads and visits, as well as the number of cited articles

Maximum dissemination of your research work

Submit your manuscript at: http://papersubmission.scirp.org/

Or contact pp@scirp.org 